\title{
DESCRIPTION OF A NEW WATER MITE SPECIES OF THE GENUS HYGROBATES KOCH, 1837 (ACARI, HYDRACHNIDIA, HYGROBATIDAE) FROM CRIMEA
}

\author{
Petr V. Tuzovsky \\ Institute for Biology of Inland Waters, Russian Academy of Sciences, Borok, Yaroslavl Prov., Russia \\ E-mail: tuz@ibiw.yaroslavl.ru
}

ABSTRACT: A description of a new water mite species from Crimea is given.

KEY WORDS: Water mite, Hygrobatidae, Hygrobates (Rivobates) alupkaensis, new species, female, male, larva.

DOI: 10.21684/0132-8077-2017-25-1-45-50

\section{INTRODUCTION}

The aim of this paper is to describe the female, male and larva of a new water mite species of the genus Hygrobates Koch, 1837 from Crimea.

Specimens were not fixed in Koenike liquid, but the slides were made from fresh materials. Most specimens were not dissected, thus preserving the natural shape of the body. For several larvae and adults the gnathosoma was mounted in a position that allowed investigating the pedipalps and chelicerae in a lateral view. To obtain larvae, water mites were maintained in the laboratory (room temperature, natural day-night conditions). Eggs and larvae obtained from females were kept individually in glass or transparent plastic vessels with diameters of 10-15 mm, and a height of $15 \mathrm{~mm}$.

In the description, nomenclature of idiosomal setae follows Tuzovsky (1987). The following abbreviations are used: P-1-5, pedipalp segments (trochanter, femur, genu, tibia and tarsus); ILeg-1-6, first leg segments 1-6 (trochanter, basifemur, telofemur, genu, tibia and tarsus) i.e. I-Leg-1= trochanter of first leg; L-length; W-width; $\mathrm{n}=$ number of specimens measured; all measurements are given in micrometers $(\mu \mathrm{m})$.

\section{DESCRIPTIONS}

\section{Hygrobates (Rivobates) alupkaensis Tuzovskij, sp.n.}

Figs. 1-20

Type material: Holotype: female, slide 1247, Crimea, Alupka city, brook in Park near Vorontsov Palace, 14 September 1975, leg. P. V. Tuzovsky. Paratypes: six males and one female collected from the same locality and data as holotype. Larvae were reared from a single female, the duration of the embryonic period was 10 day. The holotype is deposited in the collection of the Institute for Biology of Inland Waters (Borok, Russia).
Diagnosis. Adults. Integument soft and finely striated; coxal plates I posteriomedial margin convex in shape; setae Fch long and thick; coxal plate IV subrectangular with rounded medial margin; P-2 ventrodistal protrusion very short and rounded, denticulation restricted to the projection region; P-4 ventral setae separated near middle of segment, anterior seta longer and thicker than posterior one. Female: Genital plates distinctly longer than gonopore, with 6-8 acetabula and 13-17 setae. Male: posterior margin of genital plate straight or slightly convex without indentation, with 6-8 pairs of acetabula and 12-18 pairs setae. Larva: Dorsal plate elongate (L/W ratio 1.7-1.9), narrowed in anterior half, setae $P i$ and $P e$ equal in length; number of thickened setae from trochanter to tarsus on legs segments: I: 1-11-0-0, II: 0-1-2-2-0, III: 0-1-3-3-0.

Both sexes. Idiosoma oval and somewhat flattened dorsoventrally. Integument finely striated. Idiosomal setae associated with glandularia, except for trichobothria $\mathrm{Fp}, \mathrm{Oi}$ and setae $\mathrm{Pi}$. Setae Fch (Fig. 1) much thicker than other idiosomal setae. Posteromedial margin of coxal plates I broadly rounded (Fig. 2). Excretory pore unsclerotized and located anteriorly to flankig setae $(\mathrm{Ci}$ and $\mathrm{Pi})$.

Chelicera basal segment large with minute pointed dorsodistal projection, chela comparatively small sickle-shaped (Fig. 3).

Pedipalp (Fig. 4): P-1 with a single dorsodistal seta; P-2 with six short, thick dorsal setae, ventral margin proximally concave, distoventrally protruding in a very small rounded projection covered by a few denticles; P-3 with two dorsocentral, two dorsodistal setae and one or two thin dorsodistal setae, ventral margin straight or slightly concave proximally, with a few denticles covering distal half of ventral surface; P-4 longer than P-2 (P-4/P-2 


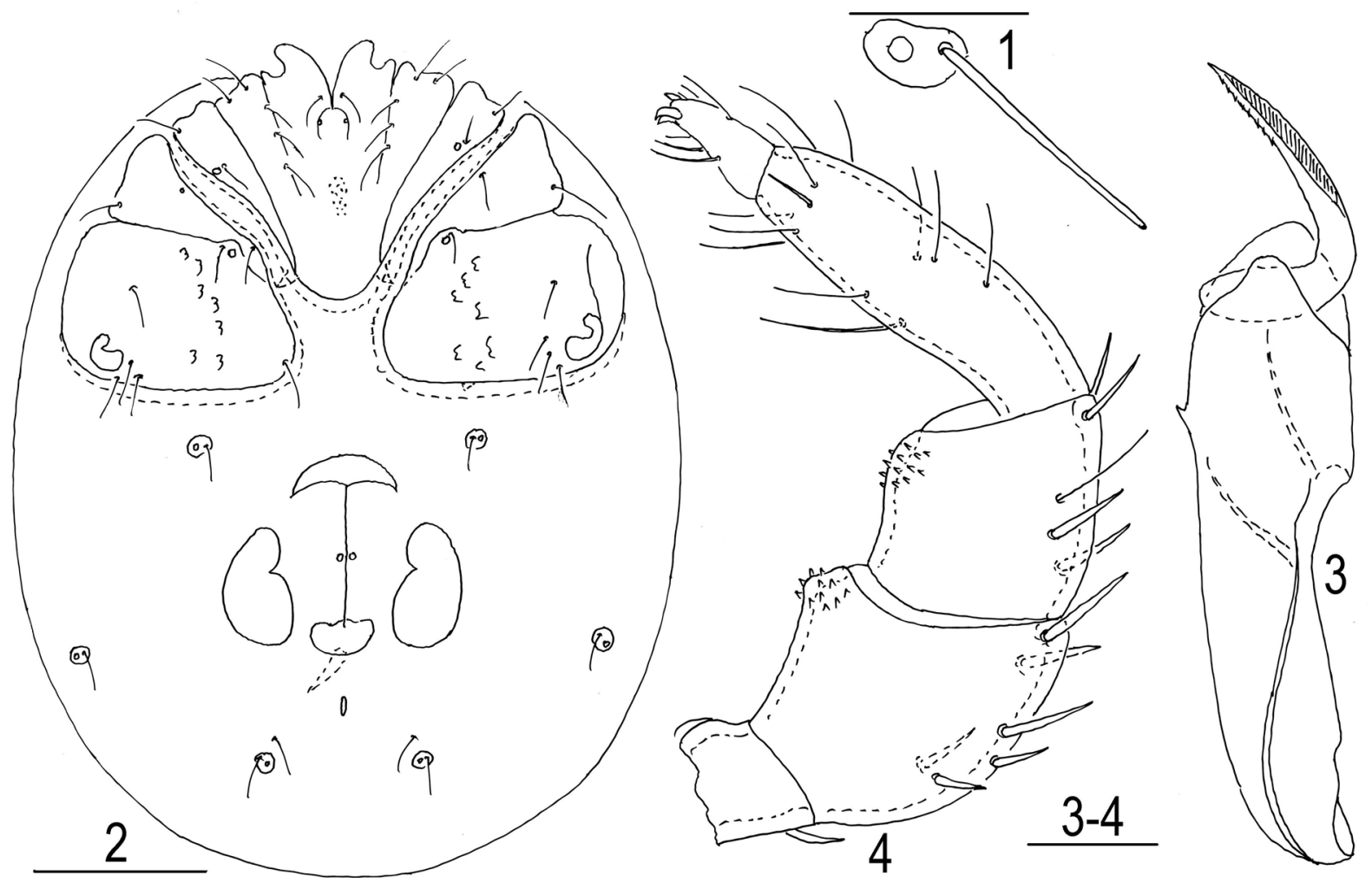

Figs. 1-4. Hygrobates alupkaensis sp.n., female: 1—seta Fch, 2-idiosoma, ventral view; 3-chelicera, 4-pedipalp. Scale bars: $1,3-4=50 \mu \mathrm{m}, 2=200 \mu \mathrm{m}$.

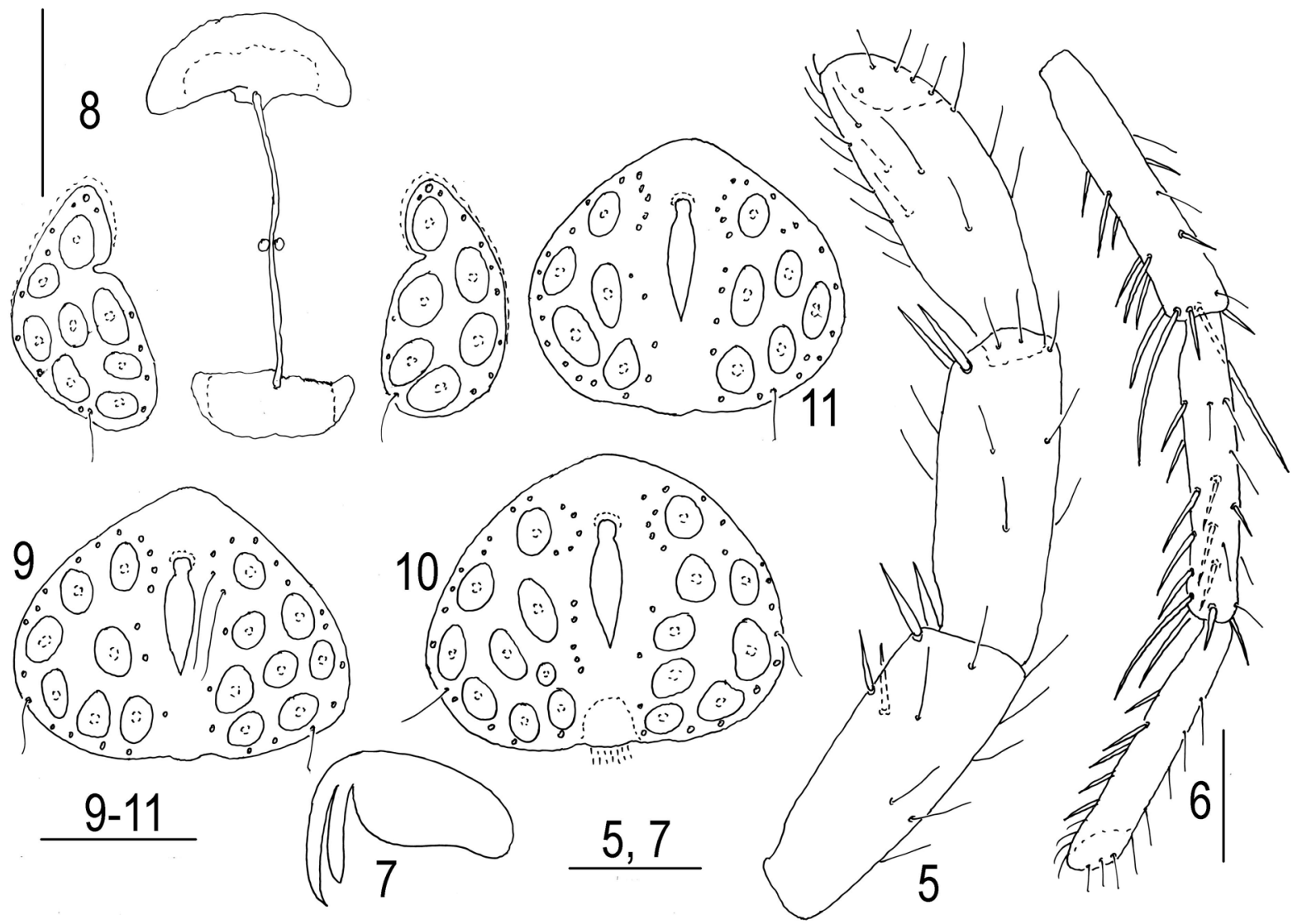

Figs. 5-11. Hygrobates alupkaensis sp.n., adults: 5-I-Leg-4-6, 6-IV-Leg-4-6, 7-leg claw, 8-11-genital field, 5-8 —female, 9-11—male. Scale bars: 5,7=50 $\mu \mathrm{m}, 6,8,9-11=100 \mu \mathrm{m}$. 

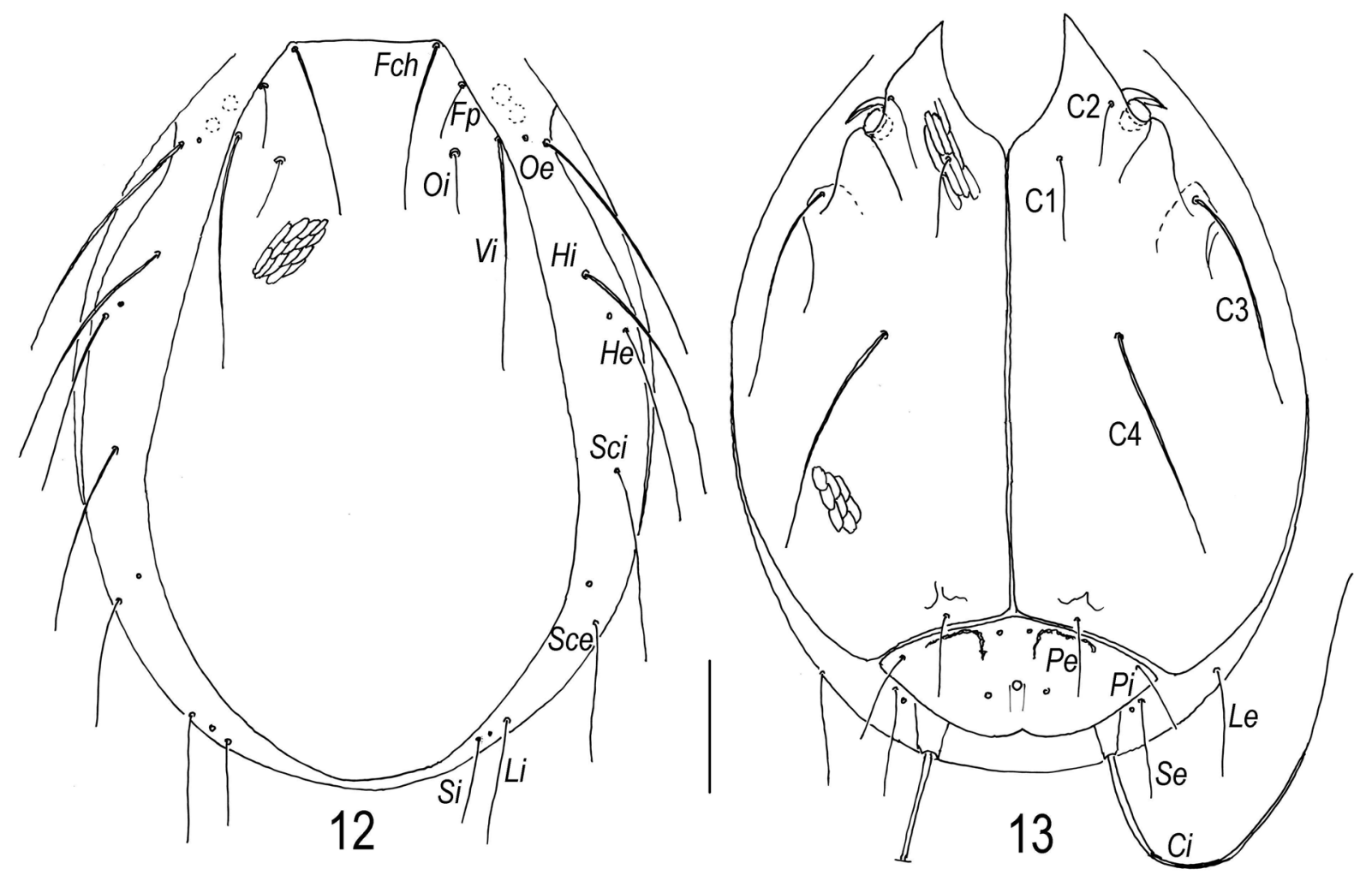

Figs. 12-13. Hygobates alupkaensis sp.n., larva: 11 -dorsal view; 12—ventral view. Scale bar: 1-2=50 $\mu \mathrm{m}$.

L ratio 1.25-1.45), ventral setae unequal in length, separated and located near middle of segment.

I-Leg-4/5 with two subequal thick distoventral setae (Fig. 5); IV-Leg-4 with five thick unequal in length distal setae, IV-Leg-5 with four unequal distal thick setae, IV-Leg-6 with four to five thick setae (Fig. 6). Claws of all legs with long external clawlet and relatively short internal one, lamella with slightly concave ventral margin (Fig. 7).

Female. Genital plates (Fig. 8) longer than wide (L/W ratio 1.7-1.9), with six to eight pairs of acetabula and 12-14 setae, medial margins indented posteriorly to anterior acetabula. Gonopore slightly longer than genital plates. Anterior genital sclerite larger than posterior one.

Measurements ( $\mathrm{n}=2)$. Idiosoma L 690-1000; seta $F$ ch L 75-80; coxal plates I + capitulum mL 250-260; genital plates L 105-120, W 55-60, cheliceral segments L: base $210-225$, chela $90-$ 100; pedipalp segments (P-1-5) L: 30-35, 90-100, 70-85, 120-130, 40-44; legs segments L: ILeg-1-6: 60-65, 90-105, 85-100, 120-135, 110135, 130-155; II-Leg-1-6: 65-70, 95-105, 90-110, 125-150, 130-155, 150-160; III-Leg-1-6: 70-65, 95-110, 105-110, 145-175, 160-190, 165-190; IV-Leg-1-6: 145-160, 140-150, 160-180, 205-235, 210-240, 195-215.
Male. Genital plate (Figs 9-11) wider than long (L/W ratio $0.7-0.9$ ), with six to eight (occasionally five, Fig. 11, or nine, Fig. 10, on one side) pairs of acetabula and 14-23 pairs of setae

Measurements $(\mathrm{n}=6)$. Idiosoma L 560-750; seta $F$ ch L 70-80; coxal plates I + capitulum mL 220-240; genital plate L 120-145, W 150-180, gonopore L 65-75; cheliceral segments L: base 200-205, chela 90; pedipalp segments $(\mathrm{P}-1-5) \mathrm{L}$ : 28-32, 90-96, 75-80, 115-120, 40-45; legs segments L: I-Leg-1-6: 50-65, 85-95, 80-85, 100-115, 110-115, 120-125; II-Leg-1-6: 50-60, 85-90, 8085, 110-120, 120-125, 130-140; III-Leg-1-6: 6065, 85-95, 95-100, 130-140, 145-160, 145-160; IV-Leg-1-6: 125-135, 115-135, 130-135, 180-195, 195-205, 170-185.

Larva. Idiosoma flat. Dorsal plate elongate (L/W ratio 1.7-1.9), in unengorged larvae covering almost the whole dorsum, with straight anterior margin, narrowed in anterior half, simple setae long and thick, but setae Fch slightly shorter than $V i$, trichobothria $\mathrm{Fp}$, Oi short, thin and equal in length (Fig. 12). Seven pairs of setae (Oe, Hi, He, Sci, Sce, $\mathrm{Li}$, Si) situated in soft membrane; $\mathrm{Oi}$ and $\mathrm{Hi}$ longest, $\mathrm{Si}$ shortest, $\mathrm{He}$ and $\mathrm{Sci}$ nearly subequal in length and longer than other posterior setae situated in the membrane. Surface of dorsal plate with reticulation. 


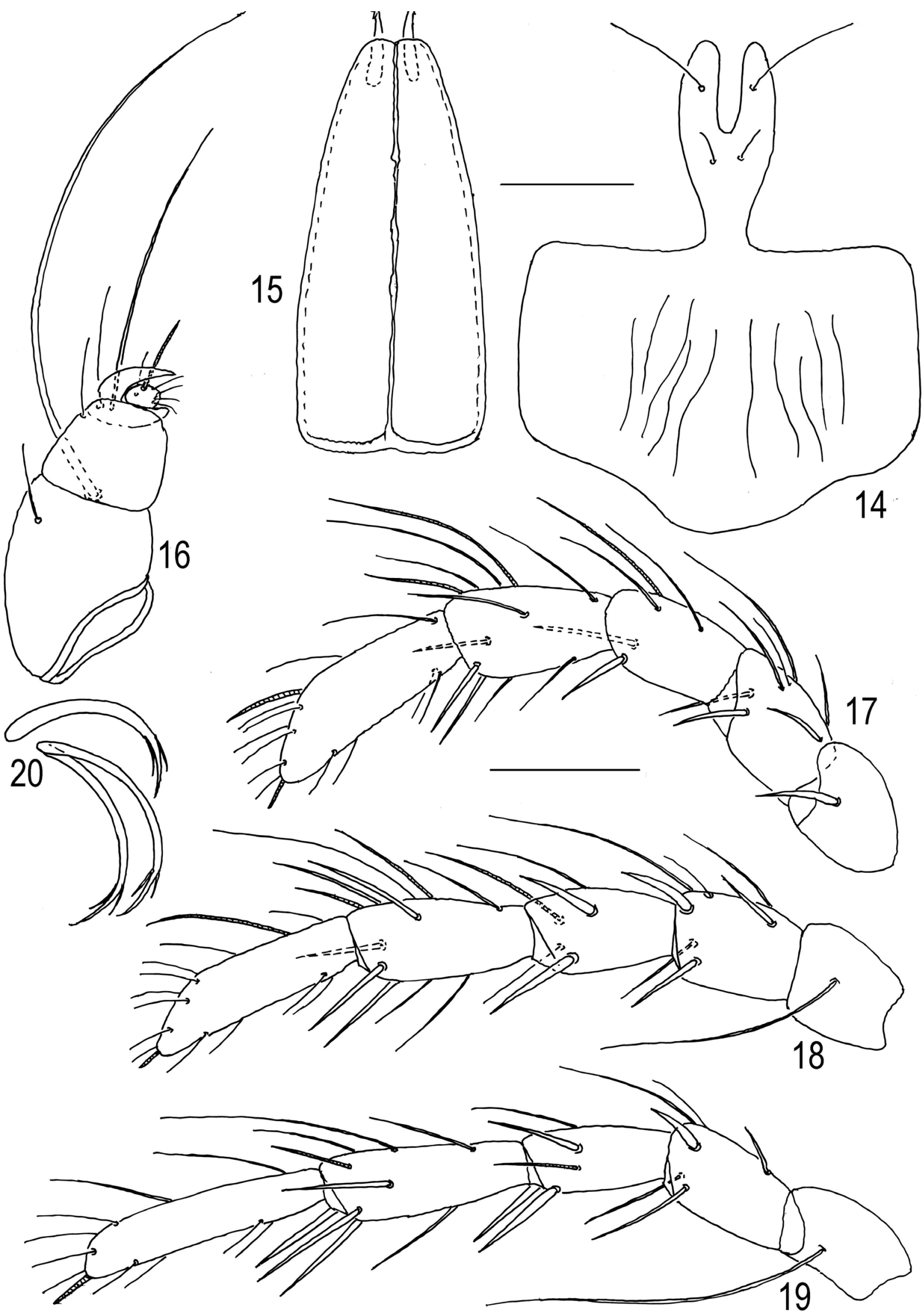

Figs. 14-20. Hygobates alupkaensis sp.n., larva: 14 - capitulum, ventral view; 15-chelicera, dorsal view; 16 - pedipalp;

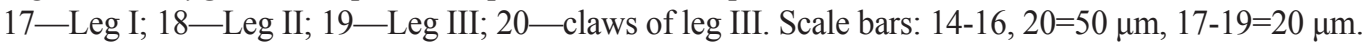



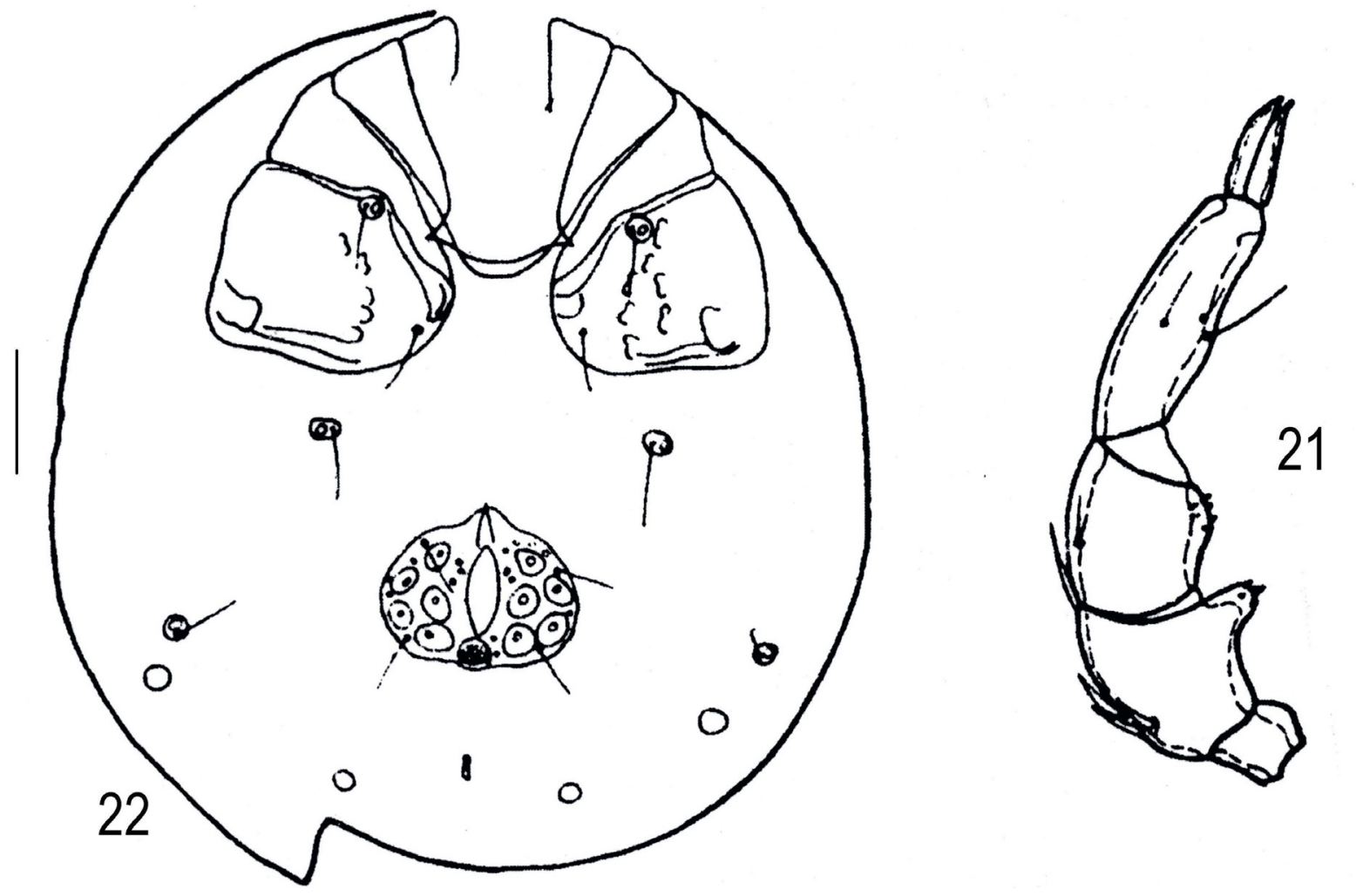

Figs. 21-22. Hygrobates quanaticola Schwoerbel et Sepasgozarian, 1976, male: 21 —pedipalp, 22 — ventral view (after Schwoerbel and Sepasgozarian 1976). Scale bars: 21-22=100 $\mu \mathrm{m}$.

Both pairs of coxal setae ( $\mathrm{C} 1$ and $\mathrm{C} 2)$ short, thin and equal in length; lateral setae (C3) slightly shorter than medial setae (C4) (Fig. 13). Transverse muscle attachment scar on coxa III absent or its rudiment present anteriorly to setae $P e$. Urstigma oval relatively large. Excretory pore plate large and broad (L/W ratio $0.45-0.50$ ), slightly convex anteriorly, W-shaped posteriorly and with muscle attachment scars anteriorly; excretory pore located slightly posterior to the center of plate. Anal setae $(A i, A e)$ reduced and represent in form of alveoli only, distance between setae $A i-A i$ slightly shorter than distance between setae $A e-A e$.

Setae $P i$ and $P e$ short, thin and equal in length. Setae $C i$ very long and well thickened, inserted on moderately long projections.

Capitulum (Fig. 14) with relatively wide base and narrow rostrum, anterior hypostomal setae much longer than posterior ones.

Basal segments of chelicerae fused to each other medially (Fig. 15), with slightly convex lateral margins. Chela relatively small, crescentshaped, with two small subapical teeth.

Pedipalps stout (Fig. 16): P-1 very short, without setae; $\mathrm{P}-2$ relatively large, with single dorsal seta near the middle of segment; $\mathrm{P}-3$ with a very long, thick lateroproximal seta and a short, fine dorsoproximal seta; $\mathrm{P}-4$ with two unequal setae and a massive dorsodistal claw; $\mathrm{P}-5$ small, with long solenidion.

Legs five-segmented. Shape and arrangement of setae, excluding eupathidia, as shown in Figs. 17-19. Number of thickened distal setae from trochanter to tarsus: I-III-Leg-1-1-1-0-0; II-0-22-3-0; III-0-1-3-3-0. Solenidion on II-Leg-5 located proximally to middle of segment, and solenidion or solenidia on other segments of legs situated distally. I/II-Leg-4 anterior solenidion longer than posterior solenidion. Claws of legs III larger than claws of legs I and II (Fig. 20).

Measurements ( $\mathrm{n}=7$ ). Dorsal plate L 270-290, W 150-160; setae Fch L 70-77; setae Vi L 80-87; setae $\mathrm{Fp}$ and $\mathrm{Oi}$ L 28-32; setae $\mathrm{Hi}$, Sci L 90-105; setae $V i$ L 48-55, setae Oe L 95-105; setae He L 80-87; setae Sce L 50-58; setae $L i$, Le L 44-52; setae $S i$ L 35-40; setae $S e$ L 28-36, setae $C i$ L 155-190, setae $P i$ and $P e$ L 28-32, setae C1 and C2 L 25-29, setae C3 L 70-80, setae C4 L 80-90; medial margins of coxae I-III L 175-182; gnatosomal bay L 44-48; urstigma L 16-19; excetory pore plate L 44-48, W 93-106; capitulum L 85-87; basal segments of chelicerae L 67-74, chela L 1619; pedipalpal segments (P-1-5) L: 3-5, 25-30, 15-19, 6-7, 3-4; legs segments L: I-Leg-1-5:28-32, 
41-45, 35-39, 41-45, 48-52; II-Leg-1-5: 30-33, 35-39, 37-40, 48-52, 60-64; III-Leg-1-5: 37-39, 35-42, 41-43, 59-61, 70-74.

Differential diagnosis. The present species is similar to Hygrobates (Rivobates) quanaticola Schwoerbel et Sepasgozarian, 1976, that has been described from Iran (Schwoerbel and Sepasgozarian 1976), and later on reported from Turkey (Erman et al. 2010). The adults of $H$. quanaticola are characterized by the large ventrodistal projection on P-2 (Fig. 21), the genital field usually with five (Fig. 22), occasionally with four (Schwoerbel and Sepasgozarian 1976) or six pairs of acetabula (Essen et al. 2013). In contrast, the adults of $H$. alupkaensis are characterized by the very small ventrodistal projection on P-2 (Fig. 4), the genital field usually with six to eight pairs of acetabula, occasionally with five or nine acetabula on each side, Figs. 10 and 11, respectively.
Etymology. The species is named after the city of Alupka, where it was collected.

Habitat. Running waters.

Distrbution. Europe, Crimea.

\section{REFERENCES}

Essen, Yu., Pešić, V., Erman, O., Kaya, Yü. 2010. New water mites of the family Hygrobatidae (Acari, Hydrachnidia) from Turkey. ZooKeys, 361: 15-25.

Schwoerbel, J. and Sepasgozarian, H. 1976. Wassermilben (Acari, Prostigmata, Hydrachnellae) aus dem Iran. 1. Mitteilung. Acta Ecologica Iranica, 1, 9-18.

Tuzovsky, P.V. 1987. Morfologiya i postembrional'noe razvitiye vodyanykh kleshchey [Morphology and Postembryonic Development in Water Mites]. Nauka Publ., Moscow, 172 pp. [in Russian] 